\title{
Plans to Accommodate Proposed Maternity Care Training Requirements: A National Survey of Family Medicine Directors of Obstetrics Curricula
}

\author{
Matthew R. Meunier, MD, Barbara S. Apgar, MD, MS, \\ Stephen D. Ratcliffe, MD, MSPH, and Patricia B. Mullan, PhD
}

Introduction: Proposed changes to family medicine maternity care training requirements, including a 2-tiered basic and advanced curriculum, have raised questions about their perceived feasibility and impact. The goal of this study was to elicit family medicine obstetrics faculty plans to adopt changes in their maternity care training of family physicians.

Methods: We surveyed obstetrics curriculum directors at 423 family medicine residency programs, eliciting their plans to accommodate proposed maternity care training requirements.

Results: Two hundred nine programs participated (49.4\% response rate). of the curriculum adoption plans reported by directors, $\mathbf{4 1 . 7 \%}$ anticipated using both curriculum models, $19.6 \%$ anticipated using the advanced model, $3.9 \%$ anticipated using the basic model, and $23.5 \%$ had no changes planned for their obstetrics curricula.

Conclusions: Most programs plan structured changes, but a significant minority of programs plan no change to their curriculum based on proposed maternity care requirements. ( $\mathrm{J}$ Am Board Fam Med 2012;25:827-831.)

Keywords: Accreditation, Competency-Based Education, Obstetrics, Medical Education

Family physicians provide critical access to quality maternity care for medically underserved settings and populations. ${ }^{1}$ Declining access to maternity care in underserved rural areas has been associated with poor perinatal outcomes. ${ }^{2,3}$ Despite the impact of family physicians on maternity care, the number of practicing family physicians providing this necessary service continues to decline. In a recent study, the proportion of U.S. family physicians practicing maternity care

This article was externally peer reviewed.

Submitted 21 May 2012; revised 8 August 2012; accepted 13 August 2012.

From the Department of Family Medicine (MRM, BSA) and the Department of Medical Education (PBM), University of Michigan Medical School, Ann Arbor, MI; and the Department of Family and Community Medicine, Lancaster General Health, Lancaster, PA (SDR).

Current affiliation: Department of Family Medicine, Mayo

Clinic College of Medicine, Rochester, MN (MRM).

Funding: none.

Conflict of interest: none declared.

Corresponding author: Matthew R. Meunier, MD, Mayo Clinic College of Medicine, 200 First Street SW, Rochester, MN 55905 (E-mail: Meunier.Matthew@mayo.edu). was found to have decreased from $23.3 \%$ in 2000 to $9.7 \%$ in $2010 .{ }^{4}$ In addition, the proportion of prenatal visits provided by family physicians has decreased from $11.6 \%$ in 1995 to 1996 to $6.1 \%$ in 2003 to $2004 .^{5}$

Complicating this disturbing trend in declining maternity care practice are increasing difficulties some residencies have encountered in providing sufficient volume of obstetric patients and faculty to train residents. ${ }^{6}$ To address these challenges, the Association of Family Medicine Residency Directors surveyed its members, performed a literature review, and conducted a discussion forum at the 2008 Annual Program Director Workshop to develop a position statement that was submitted to the Residency Review Committee (RRC) for Family Medicine. The results of this process led to the proposal of a 2-tiered model for maternity care training. The proposed changes would require all residents to perform a minimum of 20 deliveries and 200 hours of labor and delivery experience-a decrease from current standards. Residents desiring more advanced training would be 
required to perform 80 deliveries, obtain 400 hours of labor and delivery experience, and serve in the first-assistant role during Caesarian deliveries. ${ }^{7}$ These changes would provide basic training to those residents who do not plan to obtain obstetric privileges after graduating while providing delivery experience that is considered sufficient for hospital privileges to those residents intending to practice maternity care. The proposed changes to family medicine education have elicited mixed responses, with speculations about their feasibility, acceptability, and implications. ${ }^{6}$ Concerns about these proposed changes include promoting a narrow focus of practice in family medicine and worsening access to rural maternity care, in addition to concerns about the increased complexity of the medical student residency match by allowing 2 curricular options and the possibility of hospitals requiring the advanced level of training to grant maternity care privileges. ${ }^{6,8}$ Our recent survey of directors of family medicine obstetric education provides a source of empirical insight into programs' plans for obstetric training in response to the 2 -tiered training proposal.

\section{Methods}

We developed a survey of Family Medicine directors of obstetrics curricula at U.S. accredited family medicine residency programs in the context of a study examining family medicine programs' electronic fetal monitoring (EFM) teaching practices. This survey drew on a previously published national survey of accredited obstetric/gynecologic residencies about EFM training methods (with the permission of that survey's lead author). ${ }^{9}$ Questions in our survey were adjusted to focus on current methods of EFM education and the frequency of their use in Family Medicine residencies. The survey questions were piloted with a multidisciplinary panel of medical educators as well as Family Medicine obstetrics faculty from 2 institutions. The survey questions were adjusted for clarity as needed.

Given that the proposed changes to Family Medicine maternity care education would likely affect the teaching of integral topics such as EFM interpretation, our survey explicitly asked:

How will your program accommodate the upcoming changes to RRC's obstetrics requirements?

A. Will adopt the 20-delivery model.
B. Will adopt the 80-delivery model.

C. Will adopt the 20-delivery model while allowing residents to fulfill the 80 -delivery requirements with elective opportunities.

D. No plan to change the program's current curriculum based on RRC recommendations.

E. Other (please specify).

The goal of this study was to elicit responses from family medicine obstetrics faculty, augmenting the Council of Academic Family Medicine Education Research Alliance target respondents (residency program directors). Survey questions were administered as an online survey using SurveyMonkey (http://www.surveymonkey.com). Contact information for 452 U.S. accredited Family Medicine residencies were obtained from the Accreditation Council for Graduate Medical Education. ${ }^{10}$ E-mail addresses for programs without one listed by the Accreditation Council for Graduate Medical Education were obtained from the FREIDA On-line database of graduate medical programs. ${ }^{11}$ Two duplicate E-mail addresses were eliminated for universities that direct both urban and rural residency programs. The remaining $450 \mathrm{E}$-mail addresses were uploaded into a SurveyMonkey contact list. Eighteen addresses were identified as respondents who have previously "opted out" of E-mail surveys and were automatically deleted from the online survey contact list. The remaining 427 programs were sent an E-mail invitation to complete the survey and four invitations "bounced" back from undeliverable addresses. Four hundred twenty three programs received the invitation and were asked to identify the faculty member responsible for directing its obstetrics curricula. Programs were instructed to forward the survey link to those faculty members for completion of the survey. The E-mail invitation made it clear that participation in the survey was voluntary. Survey respondents were tracked using the online survey tool, and automated reminder E-mails were sent weekly, from March 12 to April 9,2012 , to programs that did not respond. $\chi^{2}$ analysis of the survey data examined trends across program demographics using SPSS software (SPSS, Inc/IBM, Chicago, IL). The final 10-question survey was submitted to the University of Michigan Institutional Review Board and was granted an educational exemption (study ID HUM00057745). 
Table 1. Distribution of Participating Programs across Defined Program Characteristics $(N=204)$

\begin{tabular}{lcc}
\hline Program & $\begin{array}{c}\text { Programs } \\
\text { Representing This } \\
\text { Category (n) }\end{array}$ & $\begin{array}{c}\text { Percentage of All } \\
\text { Participating } \\
\text { Programs }\end{array}$ \\
\hline Urban & 91 & 44.6 \\
Rural & 35 & 17.2 \\
Opposed & 70 & 34.3 \\
Unopposed & 120 & 58.8 \\
Northeast & 42 & 20.6 \\
South & 32 & 18.6 \\
Midwest & 38 & 9.4 \\
North Central & 24 & 11.8 \\
South Central & 18 & 8.8 \\
Mountain & 19 & 9.3 \\
Pacific & 27 & 13.2 \\
Military & 2 & 0.1 \\
No family medicine & 52 & 25.5 \\
$\quad$ obstetric fellows & & 74.5 \\
Family medicine & 204 & \\
$\quad$ obstetric fellows & & \\
Total & & \\
\hline
\end{tabular}

\section{Results}

Our survey elicited the participation of 209 obstetric curriculum directors (49.4\%); $97.6 \%$ of these respondents reported their plans to accommodate proposed changes to maternity care training requirements. Responding curriculum directors represented residency programs with varying demographic characteristics (Table 1). Curriculum directors reported the following: $41.7 \%$ planned to adopt both delivery models, $19.6 \%$ planned to adopt the 80 -delivery model, $3.9 \%$ planned to adopt the 20 -delivery model, and $23.5 \%$ planned no change to their obstetrics curricula based on the proposed training requirements (Figure 1). Among the remaining $11.3 \%$ of respondents, $14(61 \%)$ explained via free-text responses that their programs were undecided about their plans to accommodate the proposed requirements. Other respondents explained their plans to offer educational "tracks," and $2.0 \%$ of respondents indicated their delivery volume currently meets or exceeds the proposed training requirements. For example, one respondent wrote, "we [already] have maternity tracks - non, normal and high-[with goals of] 20, 100, 150 deliveries."

Table 2 summarizes the distribution of plans that programs reported in terms of the demographic characteristics with which the program directors related their program. Significant differ- ences $(P<.05)$ emerged in curriculum adoption plans among programs representing key demographics, including urban versus rural locations $\left(\chi^{2}=10.5 ; d f=4 ; P=.033\right)$, opposed versus unopposed programs $\left(\chi^{2}=21.1 ; d f=4 ; P=.000\right)$, geographic location $\left(\chi^{2}=74.7 ; d f=28 ; P=.000\right)$, and the presence of family medicine obstetrics fellows $\left(\chi^{2}=16.9 ; d f=4 ; P=.002\right)$ (Table 2). For example, $34.3 \%$ of rural programs planned to adopt the 80 -delivery model, whereas $14.3 \%$ of urban programs planned to do so.

\section{Discussion}

Our study provides empirical insight into how family medicine obstetrics faculty planned to accommodate proposed changes to family medicine maternity care requirements. Although the majority of programs reported plans to accommodate the proposed changes, nearly a quarter of programs-a significant minority - planned no changes to their curricula based on proposed requirement changes. This raises the question of how feasible or, perhaps, even necessary proposed policy changes may seem to key family medicine obstetrics faculty stakeholders whose participation would be critical to proposed changes. Although our survey did not explicitly ask for reasons why some programs will not change their curricula based on these proposed requirements, possible reasons include the concerning implications for the future scope of practice in family medicine; this remains an area of further research. ${ }^{6,8}$

Figure 1. Family medicine obstetrics faculty's plans for delivery requirements.

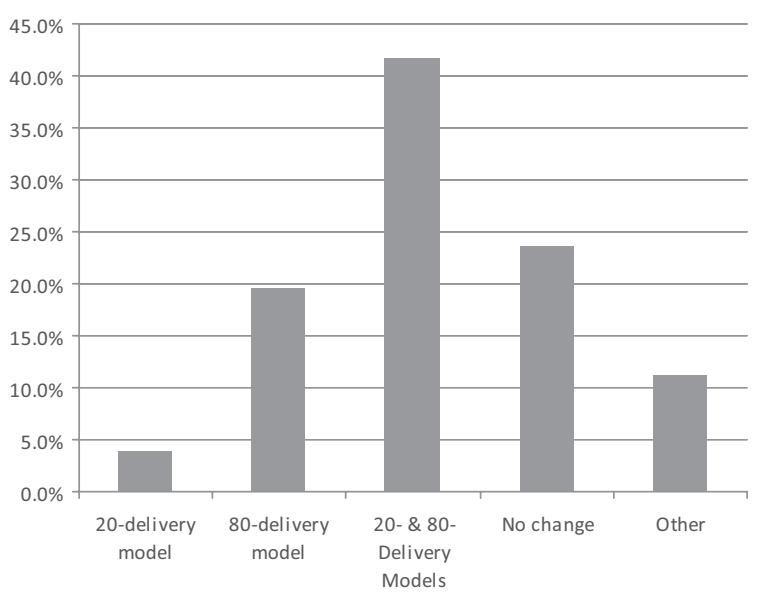


Table 2. Distribution of Planned Changes for Obstetrics Training in Family Medicine Reported by Directors of Obstetric Curricula across Defined Program Characteristics $(\mathrm{N}=204)$

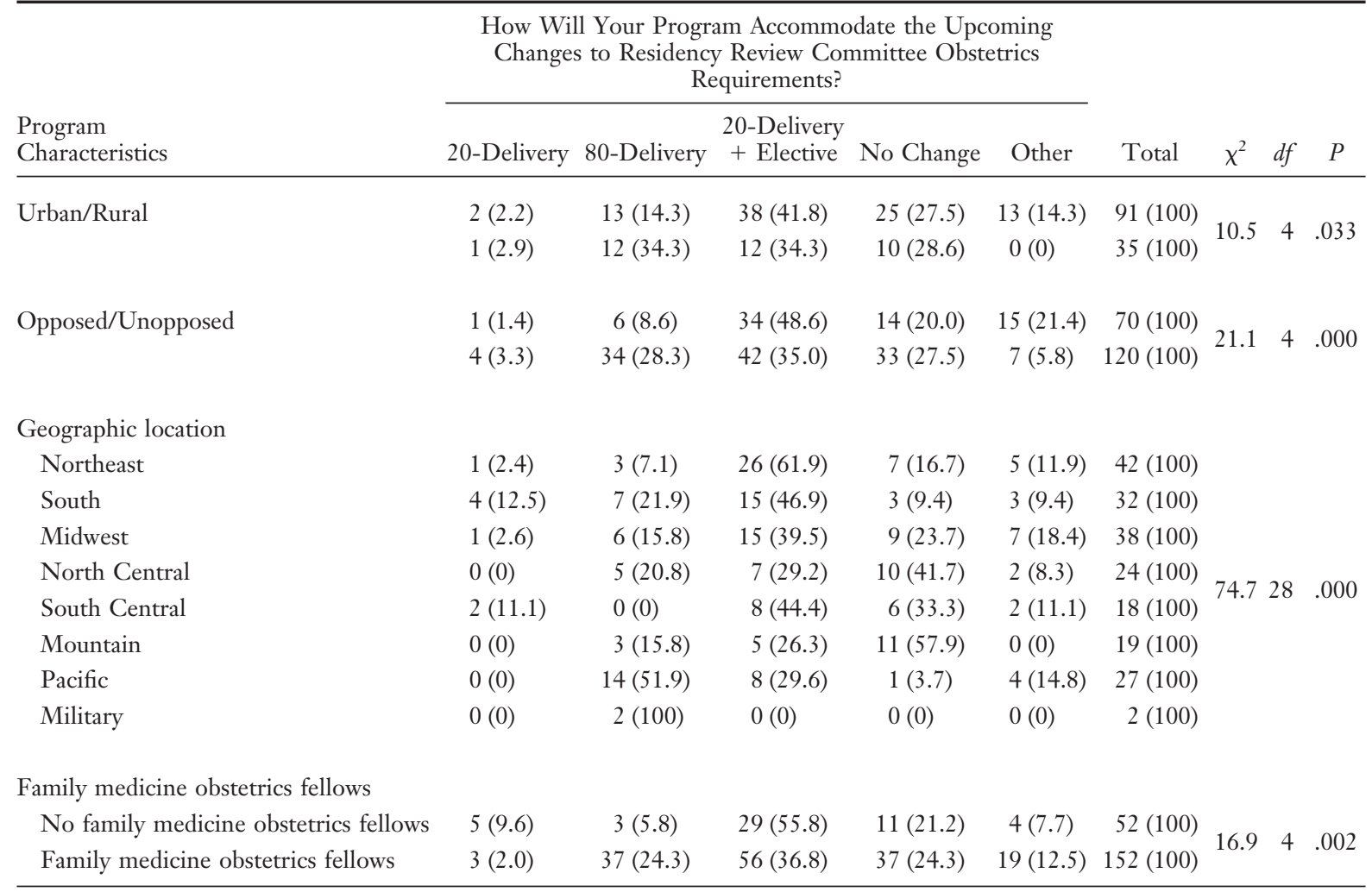

Values provided as $\mathrm{n}(\%)$.

Proposed reductions in minimal obstetrics requirements raise a concern of eroding obstetrics competencies in Family Medicine. Additional concerns regarding these changes may include the complexity for the medical student matching process, as well as trainees' potential desire to switch between minimal and more extensive obstetrics curricula during their training. Our results show that most programs plan to adopt a mixed obstetrics curriculum, which may alleviate this concern. Our results complement existing surveys by the Association of Family Medicine Residency Directors, which focused on Family Medicine residency program directors, ${ }^{12}$ and offer timely additional insights. Although the education of Family Medicine residents will continue to adapt to societal needs, this study provides empirical insight into how programs plan to accommodate changes proposed by policymakers.

\section{References}

1. Cohen D, Guirguis-Blake J, Jack B, et al. Family physicians make a substantial contribution to mater- nity care: the case of the state of Maine. Am Fam Physician 2003;68:405.

2. Nesbitt TS, Connell FA, Hart LG, Rosenblatt RA. Access to obstetric care in rural areas: effect on birth outcomes. Am J Public Health 1990;80: $814-8$.

3. Allen DI, Kamradt JM. Relationship of infant mortality to the availability of obstetrical care in Indiana. J Fam Pract 1991;33:609-13.

4. Tong S, Markaroff LA, Xierali IM, et al. Proportion of family physicians providing maternity care continues to decline. J Am Board Fam Med 2012;25: $270-1$.

5. Cohen D, Coco A. Declining trends in the provision of prenatal care visits by family physicians. Ann Fam Med 2009;7:128-33.

6. Coonrod RA, Kelly BF, Ellert W, Loeliger SF, Rodney WM, Deutchman M. Tiered maternity care training in family medicine. Fam Med 2011;43: 631-7.

7. Accreditation Council for Graduate Medical Education. Program requirements for review and comment. 2011. Available at http://www.acgme.org/ acWebsite/reviewComment/rev_programReq_Index. asp. Accessed November 1, 2011. 
8. Blanchette $\mathrm{H}$. The impending crisis in the decline of family physicians providing maternity care. J Am Board Fam Med 2012;25:272-3.

9. Murphy AA, Halamek LP, Lyell DJ, Druzin ML. Training and competency assessment in electronic fetal monitoring: a national survey. Obstet Gynecol 2003;101:1243-8.

10. Accreditation Council for Graduate Medical Education. Reports: programs by specialty (year ending
June 30, 2012). 2012. Available at http://www.acgme. org/adspublic/. Accessed November 18, 2011.

11. American Medical Association. FREIDA online. 2012. Available at https://freida.ama-assn.org/ Freida/user/viewProgramSearch.do. Accessed September 12, 2012.

12. Abercrombie S, Callaway P, Carek P, et al. A process for change: a methodology for academic family medicine. Ann Fam Med 2008.;6:569-70. 